\title{
Classifying and standardizing panfacial trauma according to anatomic categories and Facial Injury Severity Scale: a 10-year retrospective study
}

Chengzhong Lin ${ }^{1+}$, Jinyang $\mathrm{Wu}^{2+}$, Chengshuai Yang ${ }^{2}$, Chuxi Zhang ${ }^{2}$, Bing X $\mathrm{u}^{2}$, Yong Zhang ${ }^{2^{*}}$ and Shilei Zhang ${ }^{2^{*}}$

\begin{abstract}
Background: The purpose of this study was to identify the epidemiologic factors of panfacial fractures (PFs), and to evaluate the significance of anatomic PF categories and the Facial Injury Severity Scale (FISS) in classifying and standardizing panfacial injuries.
\end{abstract}

Methods: A retrospective review of all patients treated with PFs at our institution between June 2010 and April 2021 was performed. PF was defined as a concurrent fracture in at least 3 of 4 facial subunits (frontal, upper midface, lower midface, and mandible). Data regarding patient demographics, causes of injury, location of fractures, major concomitant injuries, and postinjury complications were collected, and the FISS score was collected from each patient. Statistical analysis was performed using IBM SPSS Statistics version 22.0.

Results: A total of 227 patients were enrolled. The most commonly fractured bones were the maxillary sinus wall (92.1\%), mandible (82.8\%), and zygomatic arch (75.3\%), and the most common fracture sites in PFs were graphically presented. Four PF patterns were defined: FULM $(n=60)$, FUL $(n=39), \operatorname{ULM}(n=127)$, and FUM $(n=1)$. There was a significant association between PF patterns and sex $(p=0.018)$, the number of concomitant injuries $(p=0.014)$, and early surgical airway management $(p=0.003)$. Different PF patterns were significantly correlated with different types of concomitant injuries and complications. The FISS score showed a significant difference with PF patterns $(p=0.000)$ and sex $(p=0.007)$, and a FISS value of 11 or more is the appropriate cutoff for the prediction of multiple concomitant injuries and complications.

Conclusions: Both the anatomic PF categories and FISS were significantly correlated with various concomitant injuries and complications. The combination of PF categories and FISS provided a better positive and negative prediction of concomitant injuries and complications for PF patients. Patients with FULM and FISS > 11 had an obviously higher proportion of the need for multiprofessional treatment.

\footnotetext{
*Correspondence: zhangyong1362@163.com; leinnymd@hotmail.com

${ }^{\dagger}$ Chengzhong Lin and Jinyang Wu have contributed equally to this work

${ }^{2}$ Department of Oral and Cranio-Maxillofacial Surgery, Shanghai Ninth People's Hospital, College of Stomatology, Shanghai Jiao Tong University

School of Medicine; College of Stomatology, Shanghai Jiao Tong University; National Center for Stomatology; National Clinical Research

Center for Oral Diseases, Shanghai Key Laboratory of Stomatology,

Shanghai, China

Full list of author information is available at the end of the article
}

(C) The Author(s) 2021. Open Access This article is licensed under a Creative Commons Attribution 4.0 International License, which permits use, sharing, adaptation, distribution and reproduction in any medium or format, as long as you give appropriate credit to the original author(s) and the source, provide a link to the Creative Commons licence, and indicate if changes were made. The images or other third party material in this article are included in the article's Creative Commons licence, unless indicated otherwise in a credit line to the material. If material is not included in the article's Creative Commons licence and your intended use is not permitted by statutory regulation or exceeds the permitted use, you will need to obtain permission directly from the copyright holder. To view a copy of this licence, visit http://creativecommons.org/licenses/by/4.0/. The Creative Commons Public Domain Dedication waiver (http://creativeco mmons.org/publicdomain/zero/1.0/) applies to the data made available in this article, unless otherwise stated in a credit line to the data. 
Keywords: Panfacial fracture (PF), Concomitant injury, Postinjury complication, Anatomic PF category, Facial injury severity scale

\section{Background}

Panfacial fractures (PFs) are often the result of highenergy injuries and present remarkable challenges to both surgeons and patients. These fractures are generally defined as fractures that simultaneously involve at least three out of four subunits of the facial skeleton, that is, the frontal area, upper and lower part of midfacial area, and mandibular area $[1,2]$. The various fracture patterns depend on the mechanism and degree of the externally applied forces, with the usually reported causes including traffic accidents, assaults, falls, sports and gunshot injuries. This type of trauma is often associated with emergencies, such as craniocerebral injury, thorax injury, and cervical spine injury [3-6]. Clinically, the traumatic conditions of PFs are complicated and vary between individuals.

The purpose of treating a PF patient is not only to save life but also to recover the structure, function, and aesthetics of the maxillofacial area while managing concomitant injuries effectively. The complex management of patients with multidistribution trauma requires a standardized classification for describing PF in a way that is comprehensive, measurable, validated and reproducible. Classifying PFs should be the first step toward a systemic approach for treating concomitant injuries and reducing complications $[1,7]$. Traditionally, the classification of facial injuries, such as the Le Fort system [8], proposed in terms of site distribution and anatomical impairment, helps understand their impact on morbidity and complications. However, these classification standards are insufficient in their description of more complex injuries as well as injuries to the mandible, midface and upper face, which usually occur in patients with multiple concomitant injuries and complications [9]. Recently, Jang et al. [1] performed a retrospective study of $99 \mathrm{PF}$ patients and classified the PFs into five categories according to the anatomical site of fractures, showing that different PF patterns were associated with different types of concomitant injuries and complications. It is suggested that this anatomic classification could be a potential tool, although these patterns convey qualitative but not quantitative information about the fracture patterns.

The use of a quantitative scale for facial fracture can be potentially beneficial, facilitating the proper treatment of concomitant injuries and complications and preventing irreversible damage. In addition, as a prognostic and predictive classification tool, it could simplify the communication among clinicians and patients about the extent of the injury [10, 11]. Although there have been several attempts to develop such a scale, there are still situations in which they are complex and lack true construct validity; thus, the viability of their use is in doubt. The Facial Injury Severity Scale (FISS) proposed by Bagheri et al. [12] has been widely used to grade the severity of facial injuries. The FISS was derived from predefined values of scores and weighting for fractures in different areas of the face. Not all fractures are weighted equally, and the sum of the individual scores is used to provide the final score. The FISS has been shown to be correlated with operative time, length of hospitalization and treatment cost of facial trauma and is considered to be the best communication tool available within multidisciplinary teams [13-16]. However, few studies have examined the predictive value of the FISS and the correlation of the FISS with concomitant injuries and complications among PFs patients.

Assessing and classifying PFs regarding concomitant injuries and complications will facilitate comprehensive treatment planning and multidisciplinary cooperation. However, such a well-developed clinical classification has yet to be reached. The purpose of the present retrospective study was to investigate the epidemiologic factors, concomitant injuries, complications, and FISS scores of PFs, and to verify the significance of anatomic PF categories and the FISS in classifying PF patients based on concomitant injuries and complications.

\section{Methods}

A retrospective study was carried out from the data collected in hospital charts of facial trauma patients treated in the Department of Oral and Cranio-maxillofacial Surgery, Shanghai Ninth People's Hospital, Shanghai Jiao Tong University School of Medicine between June 2010 and April 2021. The protocol of this study was reviewed and approved by the institutional review board of Shanghai Ninth People's Hospital.

\section{Classification of panfacial fractures}

The facial skeleton was divided into 4 subunits: frontal area, upper midface area, lower midface area, and mandible area (Fig. 1). Patients with fractures in at least 3 out of the 4 subunits were classified as PF according Erdmann et al. [2]. Hence, PFs can be divided into five categories: FULM, FUL, FUM, FLM, and ULM. 


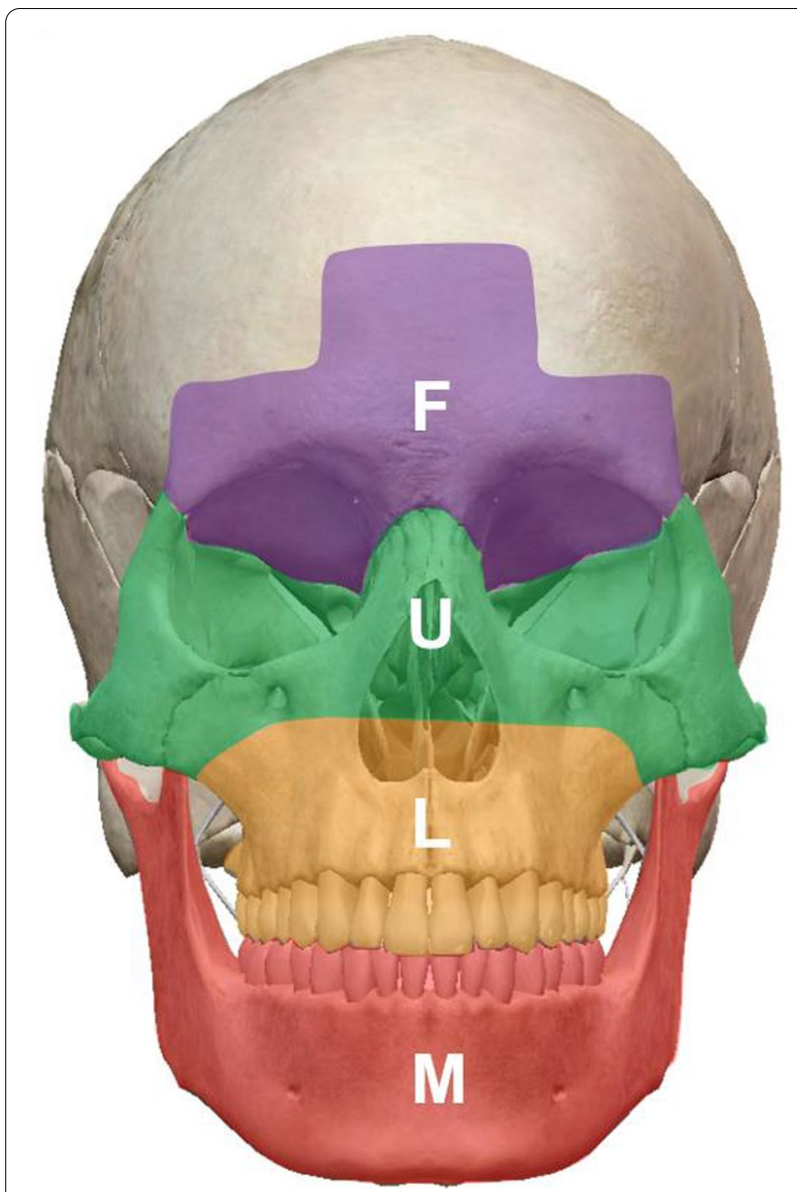

Fig. 1 Four subunits of the facial skeleton. F: frontal unit, contains frontal bone/sinus, orbital roof. U: upper midface unit, contains lateral orbital wall, medial orbital wall, orbital floor, nasal bone, NOE area, and zygomatic arch. L: lower midface unit, contains maxillary sinus, bony palate, Le fort I. M: mandibular unit, contains all mandible. ZMC fractures, Le Fort II fractures, or Le Fort III fractures were counted as fractures of both the $U$ and $L$ subunits

\section{Investigative factors}

For each PF patient, the emergency department chart, all clinic notes, all relevant radiology scans and reports were reviewed. The following data were collected for each patient:

\section{- Age/sex}

- Etiology of trauma: It was assigned as 6 categories: fall, interpersonal violence, automobile accident, bicycle/E-Bike accident, striking an object, and work accident.

- Fracture sites: The original computed tomography (CT) scan of each PF patient was reviewed to identify the exact fracture sites.

- Major concomitant injuries were classified into 5 categories: upper/lower limb injury, cervical spine
Table 1 Duke Modified Facial Injury Severity Scale (FISS)

\begin{tabular}{|c|c|}
\hline Fracture site & Score \\
\hline Frontal sinus/bone & 2 \\
\hline Orbital roof & 1 \\
\hline Lateral orbital wall & 1 \\
\hline Medial orbital wall & 1 \\
\hline Orbital floor & 1 \\
\hline Nasal & 1 \\
\hline Naso-orbito-ethmoid & 3 \\
\hline Zygomatic arch & 1 \\
\hline Zygomatico-maxillary complex & 1 \\
\hline Le Fort III & 6 \\
\hline Le Fort II & 4 \\
\hline Maxillary sinus & 1 \\
\hline Palatal & 1 \\
\hline Le Fort I & 2 \\
\hline Mandibular symphyseal & 2 \\
\hline Mandibular parasymphyseal & 2 \\
\hline Mandibular body & 2 \\
\hline Mandibular angle & 2 \\
\hline Mandibular ramus & 2 \\
\hline Mandibular sub-condylar & 1 \\
\hline Mandibular condylar & 1 \\
\hline Mandibular coronoid & 1 \\
\hline Over $10 \mathrm{~cm}$ long facial laceration & 1 \\
\hline
\end{tabular}

The FISS is the summation of the all above diagnosed fracture points in an individual patient, unless part of a complex fractures. Unilateral Le Fort fractures are assigned half the numeric value

injury, thorax injury, craniocerebral injury, and abdomen injury.

- Postinjury complications: Postinjury complications were analyzed for each patient.

- Facial Injury Severity Scale (FISS): The individual modified FISS score was calculated according to Erdmann et al. [2]. The point values of each fracture site in the FISS are outlined in Table 1.

\section{Statistical analysis}

Statistical analysis was performed using IBM SPSS Statistics version 22.0 (IBM, Armonk, NY, USA). The chi-square test was used to determine the significant differences between fracture patterns, FISS scores and sex, cause of injury, number of concomitant injuries, complications, and early surgical airway management. Student's $\mathrm{t}$ test was used to determine the significant difference between concomitant injuries, complications and FISS score values. The cutoff value of the FISS was determined by ROC curve analysis. $p<0.05$ was considered significantly different. 


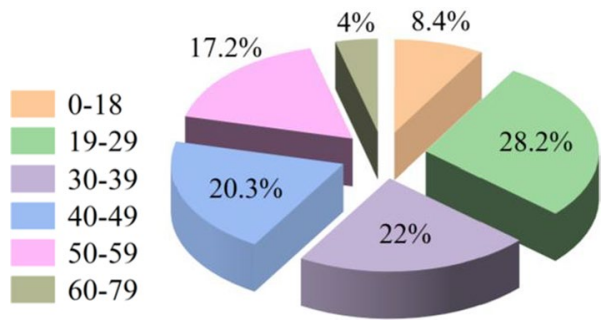

Fig. 2 Distribution of patients by age

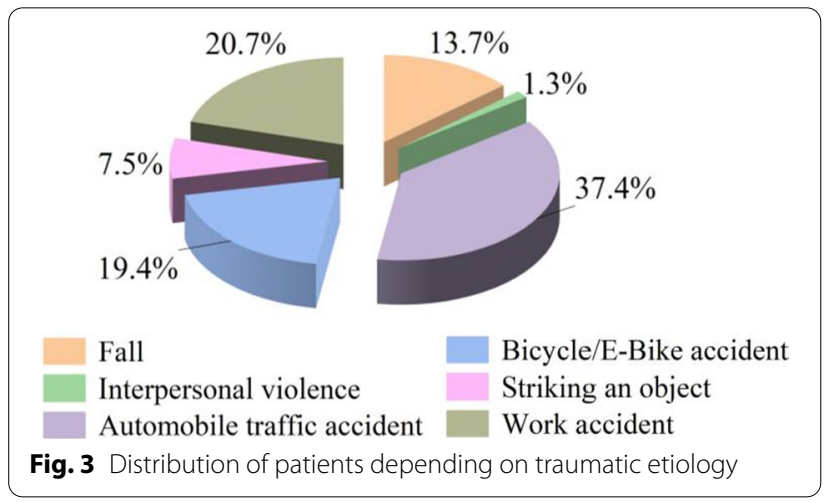

\section{Results}

\section{Etiology of panfacial injuries}

A total of 227 PF patients were analyzed for the inclusion criteria and enrolled in this study. Of these patients, 198 were male (87.2\%), 29 were female $(12.8 \%)$, and the $\mathrm{M} / \mathrm{F}$ ratio $=6.8 / 1$. The average age of the patients was $36.2 \pm 14.3$ years, ranging from 4 to 75 years of age, and the most affected age group was 19-29 years (28.2\%) (Fig. 2; Additional file 1: Table S1). The etiology of panfacial injuries differed by age group. Automobile traffic accidents (37.4\%), work accidents (20.7\%), and bicycle/E-Bike accidents (19.4\%) were the most common causes of panfacial injuries in all patients. In the pediatric group ( $0-18$ years), the rates of falls (31.5\%) and automobile traffic accidents (47.4\%) were higher than those in the other groups (Fig. 3; Table 2).

Of the 227 PF patients, the most common fracture site was the maxillary sinus wall $(92.1 \%)$, followed by the mandible $(82.8 \%)$, zygomatic arch $(75.3 \%)$, lateral orbital wall (74.9\%), and nasal bone (69.6\%). Additionally, the most common sites of mandibular fractures in PF were the symphysis/parasymphysis (52.9\%), body (22.0\%), and condyle $(20.7 \%)$. The total number of each fracture site for each mechanism of injury is presented in Table 3. In addition, the visualization of the most common fracture sites in PF cases is graphically presented in Fig. 4. The facial skull anatomic heat map revealed that these fractures usually occurred in the upper midface, such as the zygomatic arch, nasal bone, orbital floor, zygomaticomaxillary complex, naso-orbito-ethmoid complex, or in the mandibular front or collum. Le Fort III level and isolated maxillary sinus wall present a lower risk of fracture in panfacial injury patients.

\section{Anatomic panfacial fracture categories}

Regarding the anatomic PF categories, four fracture types were defined, including FULM $(n=60)$, FUL $(\mathrm{n}=39)$, ULM $(\mathrm{n}=127)$, and FUM $(\mathrm{n}=1)$. As shown in Table 4, there was no significant association between age and fracture type. The FULM pattern was mostly dominated by males (98.3\%) compared with FUL (87.2\%) and ULM (81.9\%), and there was a statistically significant association between sex and fracture type. Automobile traffic accidents were the major cause for all types of fractures. Work accidents were the second leading cause for FULM and ULM types, while bicycle/ E-bike accidents were the second leading cause for FUL types. There was no significant difference between the cause of injury and fracture types $(p=0.339)$.

Table 2 Distribution of the traumatic etiology depending on age

\begin{tabular}{|c|c|c|c|c|c|c|c|}
\hline \multirow[t]{2}{*}{ Age (y) } & \multicolumn{6}{|c|}{ Cause of injuries } & \multirow[t]{2}{*}{ Total (\%) } \\
\hline & Fall (\%) & IPV (\%) & $\mathrm{AM}$ acc $(\%)$ & B/E-B acc (\%) & SO (\%) & Work acc (\%) & \\
\hline $0-18$ & $6(31.5)$ & $0(0)$ & $9(47.4)$ & $3(15.8)$ & $1(5.3)$ & $0(0)$ & $19(100)$ \\
\hline $19-29$ & $9(14.1)$ & $1(1.6)$ & $28(43.8)$ & $12(18.8)$ & $7(10.9)$ & $7(10.9)$ & $64(100)$ \\
\hline $30-39$ & $9(18.0)$ & $0(0)$ & $17(34.0)$ & $9(18.0)$ & $2(4.0)$ & $13(26.0)$ & $50(100)$ \\
\hline $40-49$ & $5(10.9)$ & $1(2.2)$ & $16(34.8)$ & $9(19.6)$ & $4(10.9)$ & $11(23.9)$ & $46(100)$ \\
\hline $50-59$ & $2(5.1)$ & $1(2.6)$ & $11(28.2)$ & $8(20.5)$ & $1(2.6)$ & $16(41.0)$ & $39(100)$ \\
\hline $60-80$ & $0(0)$ & $0(0)$ & $4(44.4)$ & $3(33.3)$ & $2(22.2)$ & $0(0)$ & $9(100)$ \\
\hline Total & $31(13.7)$ & $3(1.3)$ & 85 (37.4) & $44(19.4)$ & $17(7.5)$ & $47(20.7)$ & $227(100)$ \\
\hline
\end{tabular}

IPV, Interpersonal violence; AM acc, Automobile accident; B/E-B acc, Bicycle/E-Bike accident; SO, Striking an object 
Table 3 Fracture locations among panfacial injuries according to the cause of injury

\begin{tabular}{|c|c|c|c|c|c|c|c|}
\hline \multirow[t]{2}{*}{ Fracture site } & \multicolumn{6}{|c|}{ Cause of injuries (A total of 227 cases) } & \multirow[t]{2}{*}{ Total (\%) } \\
\hline & Fall $(n=31)$ & IPV $(n=3)$ & $\begin{array}{l}\text { AM acc } \\
(n=85)\end{array}$ & $\begin{array}{l}\text { B/E-B acct } \\
(n=44)\end{array}$ & SO $(n=17)$ & $\begin{array}{l}\text { Work acct } \\
(n=47)\end{array}$ & \\
\hline Frontal sinus/bone & 5 & 1 & 34 & 20 & 8 & 16 & $84(37.0)$ \\
\hline Orbital roof & 6 & 1 & 21 & 10 & 7 & 14 & $59(26.0)$ \\
\hline Lateral orbital wall & 24 & 2 & 58 & 36 & 14 & 36 & $170(74.9)$ \\
\hline Medial orbital wall & 15 & 1 & 52 & 27 & 15 & 30 & $140(61.7)$ \\
\hline Orbital floor & 22 & 1 & 54 & 34 & 11 & 35 & $157(69.2)$ \\
\hline Nasal bone & 20 & 2 & 57 & 31 & 15 & 33 & $158(69.6)$ \\
\hline Naso-orbito-ethmoid & 10 & 1 & 38 & 21 & 10 & 25 & $105(46.3)$ \\
\hline Zygomatic arch & 24 & 2 & 63 & 35 & 10 & 37 & $171(75.3)$ \\
\hline Maxillary sinus wall & 30 & 3 & 76 & 40 & 16 & 44 & $209(92.1)$ \\
\hline Palatal bone & 7 & 1 & 29 & 9 & 5 & 18 & $69(30.4)$ \\
\hline Le Fort I & 5 & 0 & 17 & 15 & 1 & 9 & $47(20.7)$ \\
\hline Zygomatico-maxillary complex & 18 & 1 & 52 & 31 & 9 & 31 & $142(62.6)$ \\
\hline Le Fort II & 3 & 0 & 16 & 10 & 2 & 7 & $38(16.7)$ \\
\hline Le Fort III & 3 & 0 & 4 & 3 & 0 & 4 & $14(6.2)$ \\
\hline Mandibular symphyseal/parasymphyseal & 22 & 0 & 44 & 18 & 8 & 28 & $120(52.9)$ \\
\hline Mandibular body & 5 & 0 & 26 & 8 & 3 & 8 & $50(22.0)$ \\
\hline Mandibular angle & 2 & 0 & 7 & 4 & 3 & 3 & $19(8.4)$ \\
\hline Mandibular ramus & 1 & 1 & 14 & 5 & 0 & 10 & $31(13.7)$ \\
\hline Mandibular sub-condyle & 4 & 0 & 6 & 2 & 0 & 10 & $22(9.7)$ \\
\hline Mandibular condyle & 13 & 1 & 15 & 3 & 5 & 10 & $47(20.7)$ \\
\hline Mandibular coronoid & 1 & 0 & 4 & 6 & 0 & 1 & $12(5.3)$ \\
\hline
\end{tabular}

IPV, Interpersonal violence; AM acc, Automobile accident; B/E-B acc, Bicycle/E-Bike accident; SO, Striking an object

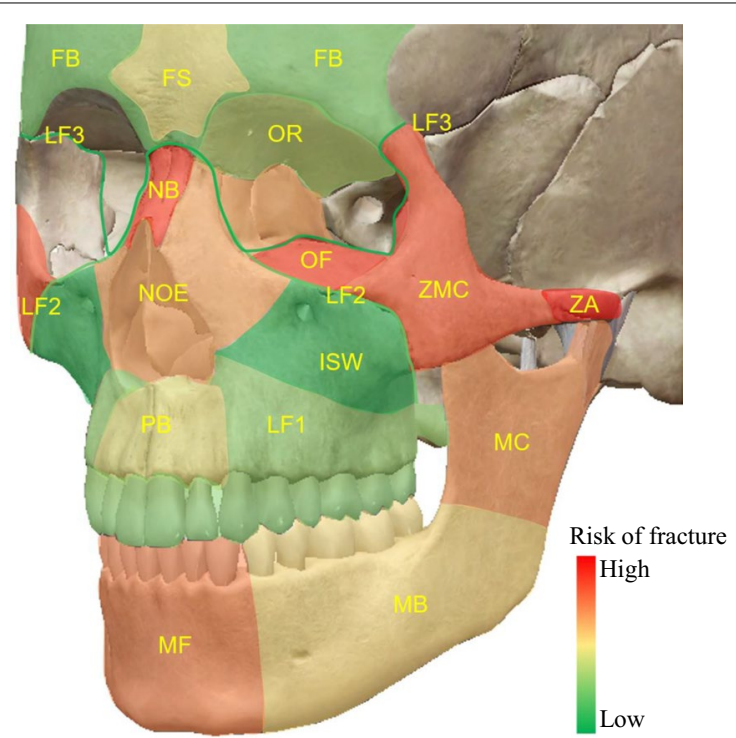

\begin{tabular}{|c|c|c|}
\hline & Fracture site & $\begin{array}{c}\text { Number of } \\
\text { cases }\end{array}$ \\
\hline ZA & Zygomatic arch & 171 \\
\hline NB & Nasal bone & 158 \\
\hline OF & Orbital floor & 157 \\
\hline ZMC & Zygomaticomaxillary complex & 142 \\
\hline MF & Frontal mandible & 120 \\
\hline MC & Mandible, collum & 112 \\
\hline NOE & Naso-orbito-ethmoid & 105 \\
\hline MB & Mandibular body, angle & 81 \\
\hline FS & Frontal sinus wall & 71 \\
\hline PB & Palatal bone & 70 \\
\hline OR & Orbital roof & 59 \\
\hline LF1 & Le Fort I & 47 \\
\hline FB & Frontal bone & 40 \\
\hline LF2 & Le Fort II & 38 \\
\hline ISW & Isolated maxillary sinus wall & 20 \\
\hline LF3 & Le Fort III & 14 \\
\hline
\end{tabular}

Fig. 4 Heat map showing the areas of the facial skeleton with a higher risk of fracture

\section{Concomitant injuries}

A total of 174 of the 227 patients had major concomitant injuries in other body parts. Traumatic craniocerebral injury was the most common concomitant injury, accounting for $46.3 \%$ of the patients in our cohort, followed by upper/lower limb injury (35.2\%), 
Table 4 Characteristics of panfacial fracture patients in relation to fracture types

\begin{tabular}{|c|c|c|c|c|c|c|}
\hline \multirow[t]{2}{*}{ Variable } & \multicolumn{5}{|c|}{ Panfacial fracture } & \multirow[t]{2}{*}{$p$ value } \\
\hline & Total & FULM (\%) & FUL (\%) & ULM (\%) & FUM (\%) & \\
\hline No. of patients & 227 & 60 & 39 & 127 & 1 & \\
\hline Mean age & $36.2 \pm 14.3$ & $37.6 \pm 12.7$ & $39.8 \pm 13.9$ & $34.5 \pm 14.9$ & 24 & 0.128 \\
\hline Sex & & & & & & $0.018^{*}$ \\
\hline Male & 198 & $59(98.3)$ & $34(87.2)$ & $104(81.9)$ & $1(100.0)$ & \\
\hline Female & 29 & $1(1.7)$ & $5(12.8)$ & $23(18.1)$ & $0(0.0)$ & \\
\hline Injury cause & & & & & & 0.339 \\
\hline Fall & 31 & $5(8.3)$ & $2(5.1)$ & $24(18.9)$ & $0(0.0)$ & \\
\hline IPV & 3 & $0(0.0)$ & $1(2.6)$ & $2(1.6)$ & $0(0.0)$ & \\
\hline AM acc & 85 & $27(45.0)$ & $13(33.3)$ & $45(35.4)$ & $0(0.0)$ & \\
\hline $\mathrm{B} / \mathrm{E}-\mathrm{B}$ acc & 44 & $11(18.3)$ & $11(28.2)$ & $21(16.5)$ & $1(100.0)$ & \\
\hline $\mathrm{SO}$ & 17 & $4(6.7)$ & $5(12.8)$ & $8(6.3)$ & $0(0.0)$ & \\
\hline Work acc & 47 & $13(21.7)$ & $7(17.9)$ & $27(21.3)$ & $0(0.0)$ & \\
\hline Concomitant injuries & & & & & & $0.014^{*}$ \\
\hline None & 53 & $9(15.0)$ & $15(38.5)$ & $29(22.8)$ & $0(0.0)$ & \\
\hline One & 85 & $16(26.7)$ & $15(38.5)$ & $54(42.5)$ & $0(0.0)$ & \\
\hline Two & 53 & $20(33.3)$ & $6(15.4)$ & $26(20.5)$ & $1(100.0)$ & \\
\hline Three or more & 36 & $15(25.0)$ & $3(7.7)$ & $18(14.2)$ & $0(0.0)$ & \\
\hline Early surgical airway & & & & & & $0.003^{*}$ \\
\hline None & 179 & $38(63.3)$ & $36(92.3)$ & $104(81.2)$ & $1(100.0)$ & \\
\hline Yes & 48 & $22(36.7)$ & $3(7.7)$ & $23(18.1)$ & $0(0.0)$ & \\
\hline
\end{tabular}

IPV, Interpersonal violence; AM acc, Automobile accident; B/E-B acc, Bicycle/E-Bike accident; SO, Striking an object; *Significant difference

thorax injury (34.8\%), abdomen injury (9.7\%), and cervical spine injury (8.8\%). The FULM type had a high incidence of two or more categories of concomitant injuries, while the FUL type showed a higher correlation with no concomitant injuries $(p=0.014$, Table 4$)$. In addition, early surgical airway management was $36.7 \%$ in the FULM type, $18.1 \%$ in the ULM type, and $7.7 \%$ in the FUL type, showing a significant difference $(p=0.003$, Table 4$)$. Regarding the investigations for each category of concomitant injuries, as shown in Table 5 and Additional file 1: Table S2, thorax injuries and craniocerebral injuries were significantly correlated with the FULM type of fractures ( $p=0.024$ and $p=0.000$, respectively), while upper/ lower limb injuries were positively correlated with the ULM type and negatively correlated with the FUL type of fractures ( $p=0.043$ and $p=0.004$, respectively).

\section{Complications}

Of all the patients, $97.8 \%$ complained of postinjury complications. The most common complication was malocclusion (83.7\%), followed by limited mouth opening (67.4\%), infraorbital nerve palsy (45.8\%), and hypopsia/ blindness (31.7\%) (Additional file 1: Table S2). On statistical evaluation, complications showed a statistically significant correlation with fracture patterns. As shown in Table 5, FULM type showed a significantly positive correlation with pneumocranium $(p=0.001)$, cerebral hematoma $(p=0.000)$, CSF leakage $(p=0.010)$, hypoacusis $(p=0.010)$, hypopsia/blindness $(p=0.024)$, and ocular movement limit $(p=0.010)$; FUL type showed a significantly positive correlation with diplopia $(p=0.001)$ and hypopsia/blindness $(p=0.004)$ and a negative correlation with traumatic facial palsy $(p=0.033)$ and malocclusion $(p=0.007)$, while ULM types showed a significantly positive correlation only with malocclusion $(p=0.015)$ and a negative correlation with other complications, such as ptosis $(p=0.015)$ and anosmia $(p=0.020)$.

\section{FISS score}

The mean FISS score assigned was $11.7 \pm 4.5$, and it was significantly higher in male patients $(p=0.007$, Table 6). There was a significant correlation between fracture patterns and FISS scores ( $p=0.000$, Table 6$)$. FULM type was related to the obviously highest FISS scores $(14.7 \pm 4.6)$, followed by FUL (11.4 \pm 3.3$)$ and ULM $(10.3 \pm 4.1)$. There was no significant difference between the cause of injuries and FISS scores $(p=0.559$, Table 6$)$. In addition, a significant difference was also found between FISS scores and concomitant injuries or complications. As shown in Table 7, statistically higher FISS scores were demonstrated in patients with major concomitant injuries, such as thorax injuries $(p=0.000)$, craniocerebral injuries 
Table 5 Statistical analysis of concomitant injuries and complications according to panfacial fracture types

\begin{tabular}{|c|c|c|c|c|c|}
\hline \multicolumn{2}{|c|}{ Characteristic } & \multirow[t]{2}{*}{ FULM $(n=60)$} & \multirow[t]{2}{*}{ FUL $(n=39)$} & \multirow[t]{2}{*}{ ULM $(n=127)$} & \multirow[t]{2}{*}{$\operatorname{FUM}(n=1)$} \\
\hline \multicolumn{2}{|c|}{ Major concomitant injuries } & & & & \\
\hline \multirow[t]{5}{*}{$p$ value } & Upper/lower limb injury $(n=79)$ & 0.963 & $0.004^{\mathrm{a}}$ & $0.043^{*}$ & / \\
\hline & Cervical spine injury $(n=20)$ & 0.879 & 0.375 & 0.395 & / \\
\hline & Thorax injury $(n=79)$ & $0.024^{*}$ & 0.092 & 0.539 & / \\
\hline & Cranio-Cerebral injury $(n=104)$ & $0.000^{*}$ & 0.989 & $0.000^{\mathrm{a}}$ & / \\
\hline & Abdomen injury $(n=22)$ & 0.925 & 0.282 & 0.447 & / \\
\hline \multicolumn{6}{|c|}{ Complications } \\
\hline \multirow[t]{14}{*}{$p$ value } & Pneumocranium $(n=34)$ & $0.001 *$ & 0.120 & $0.000^{\mathrm{a}}$ & / \\
\hline & Cerebral hematoma $(n=48)$ & $0.000^{*}$ & 0.859 & $0.000^{\mathrm{a}}$ & / \\
\hline & CSF leakage $(n=46)$ & $0.010^{*}$ & 0.177 & $0.001^{\mathrm{a}}$ & / \\
\hline & Hypoacusis $(n=12)$ & $0.010^{*}$ & 0.406 & 0.106 & / \\
\hline & Diplopia $(n=33)$ & 0.464 & $0.001 *$ & 0.091 & / \\
\hline & Hypopsia/blindness $(n=71)$ & $0.024 *$ & $0.004^{*}$ & $0.000^{\mathrm{a}}$ & / \\
\hline & Ocular movement limit $(n=49)$ & $0.010^{*}$ & 0.050 & $0.000^{\mathrm{a}}$ & / \\
\hline & Infraorbital nerve palsy $(n=104)$ & 0.097 & 0.691 & 0.098 & / \\
\hline & Epiphora $(n=31)$ & 0.220 & 0.393 & 0.092 & / \\
\hline & Anosmia $(n=26)$ & 0.141 & 0.163 & $0.020^{\mathrm{a}}$ & / \\
\hline & Ptosis $(n=35)$ & 0.254 & 0.052 & $0.015^{\mathrm{a}}$ & / \\
\hline & Traumatic facial palsy $(n=20)$ & 0.151 & $0.033^{\mathrm{a}}$ & 0.704 & / \\
\hline & Malocclusion $(n=189)$ & 0.621 & $0.007^{\mathrm{a}}$ & $0.015^{*}$ & / \\
\hline & Limited mouth opening $(n=152)$ & 0.645 & 0.393 & 0.334 & / \\
\hline
\end{tabular}

*Positive significant difference

${ }^{a}$ Negative significant difference

Table 6 Characteristics panfacial fracture patients in relation to FISS score

\begin{tabular}{lll}
\hline Variable & FISS score (SD) & p value \\
\hline Sex & $12.0(4.5)$ & $0.007^{*}$ \\
Male & $9.6(3.6)$ & \\
Female & & $0.000^{*}$ \\
Fracture type & $14.7(4.6)$ & \\
FULM & $11.4(3.3)$ & \\
FUL & $10.3(4.1)$ & \\
ULM & $12(/)$ & \\
FUM & & \\
Injury cause & $11.5(5.0)$ & \\
Fall & $8.3(5.0)$ & \\
Interpersonal violence & $11.4(4.2)$ & \\
Automobile accident & $11.8(4.4)$ & \\
Bicycle/E-bike accident & $11.6(3.8)$ & \\
Striking an object & $12.6(4.8)$ & \\
Work accident & & \\
Concomitant injuries & $10.4(4.5)$ & \\
None & $10.9(4.3)$ & \\
One & $13.0(4.2)$ & \\
Tow & $13.4(4.4)$ & \\
Three or more & & \\
\hline Signfcantdffen & & \\
\hline
\end{tabular}

* Significant difference $(p=0.027)$, and abdomen injuries $(p=0.031)$, and complications, such as hypoacusis $(p=0.004)$, cerebral hematoma $(p=0.024)$, anosmia $(p=0.002)$, and early surgical airway management $(p=0.000)$. Moreover, we performed ROC curve analysis to determine the value of the FISS score for the prediction of major concomitant injuries in patients with panfacial trauma, and the optimal cutoff value for the FISS score was 10.5 (AUC $=0.672,95 \% \mathrm{CI}$ 0.600-0.744, Additional file 1: Figure S1). We then classified the PF patients into a high FISS group (FISS $\geq 11$, $\mathrm{n}=124$ ) and a low FISS group (FISS $<11, \mathrm{n}=103$ ). Consistent with Table 7, the high FISS group showed a significant correlation with thorax injuries, craniocerebral injuries, early airway management, and the majority of complications (Additional file 1: Table S3).

To present the risks of concomitant injuries and complications of panfacial trauma more accurately and intuitively, we developed a modified model that combined the assessment of anatomic PF categories and the FISS. Patients diagnosed with PFs were defined into 6 groups, including FULM\&FISS $\geq 11$ group, FULM\&FISS $<11$ group, FUL\&FISS $\geq 11$ group, FUL\&FISS $<11$ group, ULM\&FISS $\geq 11$ group, ULM\&FISS $<11$ group, except the FUM type, which accounted for only one patient. Statistically, more detailed correlation between the panfacial 
Table 7 Statistical analysis of concomitant injuries and complications in relation to FISS score

\begin{tabular}{|c|c|c|c|}
\hline \multirow[t]{2}{*}{ Characteristics } & \multicolumn{2}{|c|}{ FISS score (SD) } & \multirow[t]{2}{*}{$p$ value } \\
\hline & Yes & None & \\
\hline \multicolumn{4}{|l|}{ Major concomitant injuries } \\
\hline Upper/lower limb injury & $11.9(4.6)$ & $11.6(4.5)$ & 0.55 \\
\hline Cervical spine injury & $12.9(3.8)$ & $11.6(4.5)$ & 0.224 \\
\hline Thorax injury & $13.1(4.7)$ & $10.9(4.2)$ & $0.000 *$ \\
\hline Cranio-cerebral injury & $12.4(4.2)$ & $11.1(4.7)$ & $0.027^{*}$ \\
\hline Abdomen injury & $13.6(4.1)$ & $11.5(4.5)$ & $0.031 *$ \\
\hline \multicolumn{4}{|l|}{ Complications } \\
\hline Early surgical airway & $14.67(4.53)$ & $10.88(4.14)$ & $0.000^{*}$ \\
\hline Pneumocranium & $12.9(3.7)$ & $11.5(4.6)$ & 0.091 \\
\hline Cerebral hematoma & $13.0(3.8)$ & $11.3(4.6)$ & $0.024 *$ \\
\hline CSF leakage & $12.6(4.4)$ & $11.4(4.5)$ & 0.118 \\
\hline Hypoacusis & $15.3(5.5)$ & $11.5(4.4)$ & $0.004 *$ \\
\hline Diplopia & $13.1(4.4)$ & $11.4(4.5)$ & 0.056 \\
\hline Hypopsia/blindness & $13.4(4.8)$ & $10.9(4.1)$ & $0.000 *$ \\
\hline Ocular movement limit & $13.1(4.6)$ & $11.3(4.4)$ & $0.013^{*}$ \\
\hline Infraorbital nerve palsy & $12.5(4.6)$ & $10.9(4.3)$ & $0.007^{*}$ \\
\hline Epiphora & $14.4(5.3)$ & $11.3(4.2)$ & $0.000^{*}$ \\
\hline Anosmia & $14.3(4.1)$ & $11.3(4.4)$ & $0.002 *$ \\
\hline Ptosis & $12.0(4.3)$ & $11.6(4.5)$ & 0.621 \\
\hline Traumatic facial palsy & $12.5(4.7)$ & $11.6(4.5)$ & 0.395 \\
\hline Malocclusion & $11.9(4.6)$ & $10.6(3.9)$ & 0.126 \\
\hline Limited mouth opening & $11.9(4.7)$ & $11.3(4.0)$ & 0.321 \\
\hline
\end{tabular}

${ }^{*}$ Significant difference

fractures and concomitant injuries or complications were presented compared with the anatomic PF categories or FISS scores alone (Table 8, Additional file 1: Table S4-S5). Interestingly, the heat map could provide a good visualization of the risk of concomitant injuries and complications among each new group (Fig. 5).

\section{Discussion}

The definition of PFs is still controversial. Some studies deemed that exact PF must simultaneously involve the upper, middle, and lower thirds of the face $[17,18]$. Other studies often considered that fractures involving two out of the three thirds of the face are sufficient to be classified as PF $[19,20]$. Recently, some researchers defined the facial skeleton into four segments, including the frontal, upper, and lower parts of the midfacial and mandibular subunits, and proposed that facial fractures involving at least three out of four subunits can be defined as PF [1, 2]. This is also generally accepted. In the present study, we defined PFs as involving at least three out of four subunits of the face; accordingly, of all 227 patients reviewed, three major patterns were defined: FULM $(n=60)$, FUL $(n=39)$, ULM $(n=127)$, and only one patient classified as FUM. All patients suffered from fractures in the upper midface. This result was in line with a study of $99 \mathrm{PF}$ patients performed by Jang et al. [1].

The most common fracture sites in our study were the maxillary sinus wall, followed by the mandible, zygomatic arch, nasal bone, orbital floor, zygomaticomaxillary complex, and Naso-orbito-ethmoid complex. As described by Park et al. [6], the most common fracture sites in their study of PFs were mandible, frontozygomaticomaxillary complex, and nasal bone. Dalena et al. [5] also proposed that the most common fracture sites of PFs were the orbital, front sinus, nasal bone and mandible. These data suggested that mandibular fractures and complex fractures of the upper midface were more likely to occur in panfacial injuries. Additionally, the type of distribution of mandibular fractures in PFs was described in the present study. The mandibular symphysis/parasymphysis, body, and condyle were the most common sites suffering panfacial injuries, which was in line with the study by Yang et al. [21]. We further developed a facial skeleton anatomic heat map estimating the level of fracture risks in panfacial injury patients. This heat map was proposed for the first time and provided a clear visualization that fractures in the upper midface, such as the zygomatic arch, nasal bone, orbital floor, zygomaticomaxillary complex, naso-orbito-ethmoid complex, or in the mandibular front and collum, were most likely to occur in panfacial injury patients.

Facial fractures are more prevalent in males, and there was a tendency in the present study (male/ female $=6.8 / 1$ ). In terms of the PF patterns, the FULM type was significantly more dominant in males than the FUL and ULM types. The most common etiology for all types of fractures was automobile traffic accidents, which was consistent with other studies. Work accidents were the second most common cause of FULM and ULM types, and bicycle/E-bike accidents were the second most common cause of FUL types. In addition, falls were another frequent cause, especially for the ULM type. Road traffic accidents such as automobile accidents and bicycle/E-Bike accidents are both correlated with injuries at high velocity and impact; accordingly, efforts should be made to increase traffic safety to reduce the incidence of these injuries.

According to the multicenter study conducted by Brucoli et al., the most frequent cause of maxillofacial injury was fall, while zygomatic fractures were the most frequently encountered injuries. Falls from a height were associated with a low FISS value with no associated concomitant injuries, while concomitant injuries were seen in $27.3 \%$ of patients. The study emphasized the frequency of involvement of females, and the high frequency of zygomatic fractures [22-24]. An absence of specific and 
Table 8 Statistical analysis of concomitant injuries and complications according to modified panfacial fracture patterns

\begin{tabular}{|c|c|c|c|c|c|c|c|}
\hline \multicolumn{2}{|c|}{ Characteristics } & FULM FISS $\geq 11$ & FULM FISS $<11$ & FUL FISS $\geq 11$ & FUL FISS $<11$ & ULM FISS $\geq 11$ & ULM FISS $<11$ \\
\hline \multicolumn{8}{|c|}{ Major concomitant injuries } \\
\hline \multirow[t]{5}{*}{$p$ value } & Upper/lower limb injury & 0.644 & 0.488 & 0.164 & $0.048^{\mathrm{a}}$ & 0.377 & 0.177 \\
\hline & Cervical spine injury & 0.737 & 0.390 & 1.000 & 0.347 & 0.057 & 0.423 \\
\hline & Thorax injury & $0.010^{*}$ & 1.000 & 0.177 & 0.514 & 0.050 & $0.016^{\mathrm{a}}$ \\
\hline & Cranio-cerebral injury & $0.000 *$ & 0.062 & 0.895 & 0.872 & 0.764 & $0.000^{\mathrm{a}}$ \\
\hline & Abdomen injury & 0.532 & 0.608 & 1.000 & 0.301 & 0.295 & 0.898 \\
\hline \multicolumn{8}{|c|}{ Complications } \\
\hline \multirow[t]{15}{*}{$p$ value } & Early surgical airway & $0.000 *$ & 1.000 & 0.276 & 0.165 & 0.053 & $0.002^{\mathrm{a}}$ \\
\hline & Pneumocranium & $0.000^{*}$ & 1.000 & 0.234 & 0.580 & 0.217 & $0.002^{\mathrm{a}}$ \\
\hline & Cerebral hematoma & $0.000 *$ & $0.025^{*}$ & 0.795 & 0.818 & 0.393 & $0.000^{\mathrm{a}}$ \\
\hline & CSF leakage & $0.006^{*}$ & 1.000 & 0.671 & 0.151 & 0.566 & $0.000^{\mathrm{a}}$ \\
\hline & Hypoacusis & $0.016^{*}$ & 1.000 & 1.000 & 0.620 & 0.861 & 0.356 \\
\hline & Diplopia & 0.566 & 1.000 & $0.001 *$ & 0.538 & 0.274 & $0.010^{\mathrm{a}}$ \\
\hline & Hypopsia/blindness & $0.002 *$ & 0.245 & $0.033^{*}$ & 0.082 & 0.127 & $0.001^{\mathrm{a}}$ \\
\hline & Ocular movement limit & 0.043 & 0.292 & 0.170 & 0.207 & 0.393 & $0.002^{\mathrm{a}}$ \\
\hline & Infraorbital nerve palsy & 0.050 & 0.958 & 0.526 & 0.903 & 0.490 & $0.018^{\mathrm{a}}$ \\
\hline & Epiphora & 0.936 & $0.044^{*}$ & 0.155 & 1.000 & 0.073 & $0.001^{\mathrm{a}}$ \\
\hline & Anosmia & 0.255 & 0.719 & 0.431 & 0.735 & 0.131 & $0.000^{\mathrm{a}}$ \\
\hline & Ptosis & 0.898 & $0.028^{*}$ & 0.264 & 0.130 & 0.656 & $0.030^{\mathrm{a}}$ \\
\hline & Traumatic facial palsy & 0.370 & 0.480 & 0.275 & 0.347 & 0.178 & 0.423 \\
\hline & Malocclusion & 0.948 & 0.446 & 0.110 & $0.041^{\mathrm{a}}$ & 0.137 & 0.218 \\
\hline & Limited mouth opening & 0.812 & 0.868 & 0.573 & 0.553 & 0.320 & 0.892 \\
\hline
\end{tabular}

*Positive significant difference

${ }^{\text {a }}$ Negative significant difference

predefined indications to treatment was associated with comorbidities. Elderly patients require specific attention and multidisciplinary collaboration in the diagnosis and sequencing of trauma treatment. A prudent attitude may be kept in selected cases, especially when severe comorbidities are associated and function is not impaired [25, 26].

PFs are frequently associated with various life-threatening concomitant injuries and complications, the causes of which are usually large external forces [3-5]. Hwang et al. [27] reported that neurological disorders and ophthalmic complications were the most common complications in patients with PFs. In the present study, 97.8\% of the patients suffered concomitant injuries or postinjury complications, with five departments found to be mostly involved in managing these problems: neurosurgery, orthopedic surgery, ophthalmology, otolaryngology, and thoracic surgery. Based on fracture patterns, the patients suffering from FULM-type fractures had a significantly higher proportion of concomitant injuries and complications. The FULM type showed a significant correlation with thorax injuries, craniocerebral injuries, and complications, including pneumocranium, cerebral hematoma, CSF leakage, hypoacusis, hypopsia/blindness, and ocular movement limit. While the FUL type showed a significant correlation with diplopia and hypopsia/blindness, the ULM type showed a significant correlation with limb injuries and malocclusion. Additionally, early airway management is another major concern in the treatment of panfacial injuries. Over one-fifth of our patients required a surgical airway upon arrival or prior to arrival at the trauma bay. In terms of fracture patterns, early surgical airway management was most frequently performed in FULM- and ULM-type fractures. This suggests that surgeons in charge of panfacial injury patients must have a high index of suspicion for these life-threatening injuries. While the probability of concomitant injuries and complications correlated with each type of PF pattern were different, classifying patients first will therefore help the treating clinicians cooperate rapidly and closely with the relevant departments.

Another finding in the present study was that the FISS can be applied to evaluate the risk of concomitant injuries and complications of panfacial injuries. At present, a number of facial injury severity systems have been proposed, such as the Craniofacial Disruption Score (CDS) [28], Maxillofacial Injury Severity Scores (MFISS) [29], Facial Fracture Severity Score (FFSS) [30], FISS [12], and 


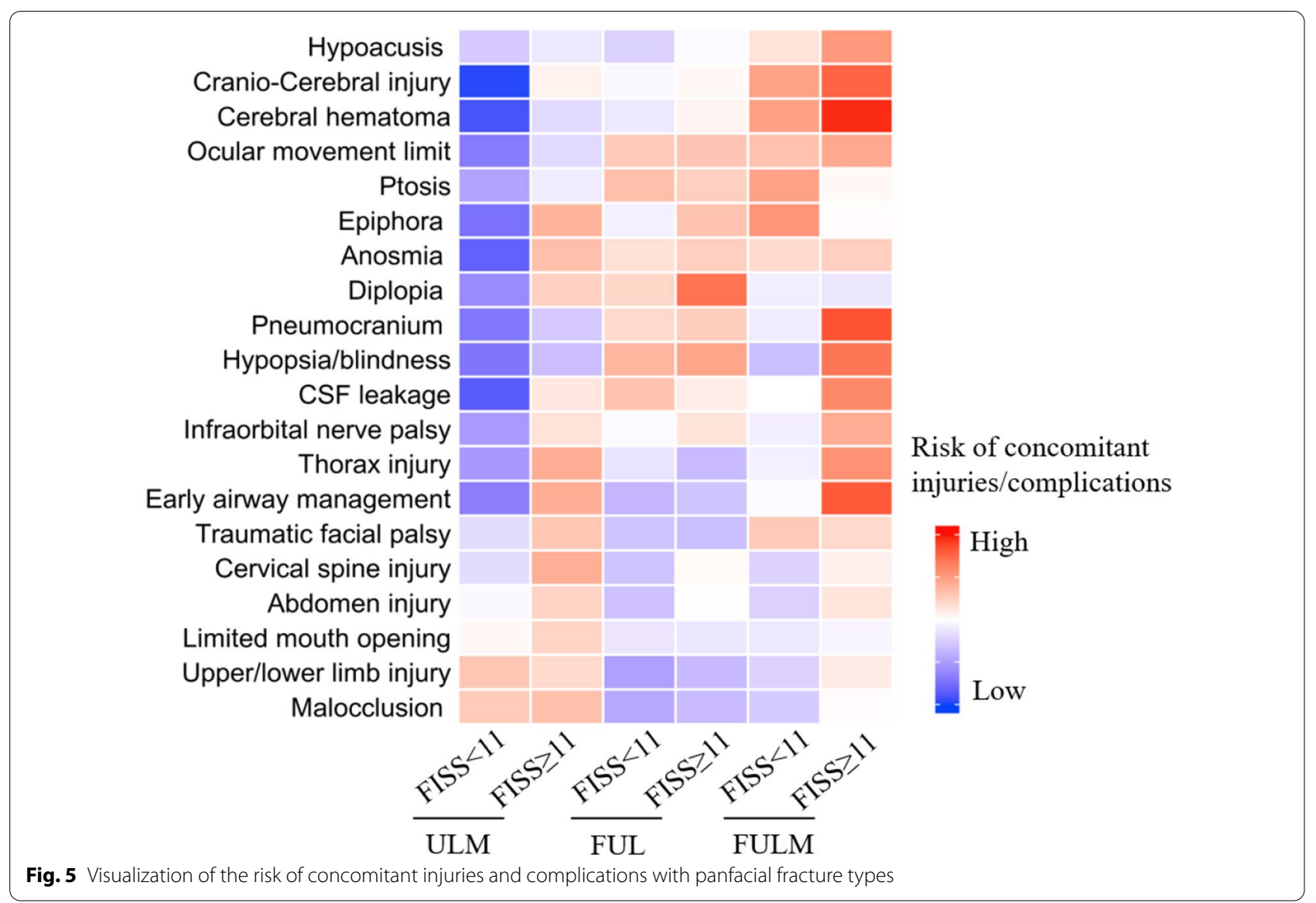

the ZS model [10]. A series of studies have been performed regarding the evaluation or comparison of facial fracture patients with various types of injury scales. The FISS has been considered to be the best available communication tool for multidisciplinary teams. Researchers have demonstrated that a higher FISS score indicates a strong correlation with specialist surgery, high treatment costs, and long hospitalization [13-16]. Aita et al. [13] showed that patients with FISS $>5$ presented 18 times the chance of needing surgical intervention in the OR and a greater possibility of hospitalization longer than 3 days. In terms of panfacial injuries, there are still no studies performed with regard to the correlation between FISS and concomitant injuries and complications. Based on the present study, a significant association was found between the FISS scores and PF patterns, concomitant injuries, and complications, and a FISS value of 11 or more was the appropriate cutoff for the prediction. The results revealed that PFs with FISS $\geq 11$ were significantly correlated with multiple concomitant injuries and complications, requiring involvement of other specialties. This finding is also of great value to prompt communication within multidisciplinary teams.
In the present study, we revealed that both the anatomic PF categories and FISS were significantly correlated with several concomitant injuries and complications. The combined assessment of these two variables was then performed in an attempt to further propose a better prediction of concomitant injuries and complications for panfacial injury patients. As expected, our modified model provided a more accurate correlation between panfacial fractures and concomitant injuries or complications. Additionally, the heat map presented a good positive and negative predictive visualization of concomitant injuries and complications. Canzi et al. [31, 32] developed the comprehensive facial injury (CFI) score, which originated from the FISS system, and classified facial fractures into 6 clusters according to the range of CFI scores, which was significantly correlated with overall surgical time and length of hospitalization. In our study, this was the first study to classify PF patients based on the combination of anatomic PF categories and the FISS system, and this model has demonstrated potential predictive value. 


\section{Conclusions}

In the present study, we investigated various factors associated with PFs, including patient demographics, causes of injury, location of fractures, major concomitant injuries, and postinjury complications. The most common fractured bones of PFs were the maxillary sinus wall, mandible, zygomatic arch, lateral orbital wall, and nasal bone. Traumatic craniocerebral injury, limb injury, and thorax injury were the most common concomitant injuries. There was a significant association between PF patterns and sex, concomitant injuries, early surgical airway management, and complications. Different PF patterns were significantly correlated with different types of concomitant injuries and complications. The FISS score also showed a significant difference with PF patterns, sex, concomitant injuries and complications. A FISS value of 11 or more is the appropriate cutoff for the prediction. We further proposed that the combination of PF categories and FISS can provide a better positive and negative prediction of concomitant injuries and complications for PF patients. It is suggested that this combined model could be a potential tool for the classification of PFs and therefore for the integration of multidisciplinary teams. Classifying PFs should be the first step toward systemic treatment.

\section{Abbreviations \\ PF: Panfacial fracture; FISS: Facial Injury Severity Scale; F: Frontal area; U: Upper midface area; L: Lower midface area; M: Mandible area.}

\section{Supplementary Information}

The online version contains supplementary material available at https://doi. org/10.1186/s12903-021-01900-w.

Additional file 1. Supplementary statistical analysis.

\section{Acknowledgements}

Not applicable.

\section{Authors' contributions}

CZL and JYW wrote the manuscript. CZL, JYW, CSY, and CXZ collected the data and conducted the statistical analysis. SLZ, YZ, and BX modified the paper and designed the study concepts. All authors read and approved the final manuscript.

\section{Funding}

This work was supported by the Shanghai Science and Technology Committee (20S31902200 and 20XD1433400), and Shanghai Ninth People's Hospital, Shanghai Jiao Tong University School of Medicine (JYLJ201918076, JYJC201802 and MDT project 201906).

\section{Availability of data and materials}

The datasets used and/or analyzed during the current study are available from the corresponding author on reasonable request.

\section{Declarations}

Ethics approval and consent to participate

This study was approved by the institutional review board of Shanghai Ninth People's Hospital (No. SH9H-2019-T242-2). This study was performed in accordance with the Declaration of Helsinki and its amendments.

\section{Consent for publication}

Not applicable.

\section{Competing interests}

The authors declare that they have no competing interests.

\section{Author details}

${ }^{1}$ The 2nd Dental Center, Shanghai Ninth People's Hospital, College of Stomatology, Shanghai Jiao Tong University School of Medicine; College of Stomatology, Shanghai Jiao Tong University; National Center for Stomatology; National Clinical Research Center for Oral Diseases, Shanghai Key Laboratory of Stomatology, Shanghai, China. ${ }^{2}$ Department of Oral and Cranio-Maxillofacial Surgery, Shanghai Ninth People's Hospital, College of Stomatology, Shanghai Jiao Tong University School of Medicine; College of Stomatology, Shanghai Jiao Tong University; National Center for Stomatology; National Clinical Research Center for Oral Diseases, Shanghai Key Laboratory of Stomatology, Shanghai, China.

Received: 9 August 2021 Accepted: 12 October 2021

Published online: 01 November 2021

\section{References}

1. Jang SB, Choi SY, Kwon TG, Kim JW. Concomitant injuries and complications according to categories of pan-facial fracture: a retrospective study. J Craniomaxillofac Surg. 2020;48(4):427-34.

2. Erdmann D, Follmar KE, Debruijn M, Bruno AD, Jung SH, Edelman D, Mukundan S, Marcus JR. A retrospective analysis of facial fracture etiologies. Ann Plast Surg. 2008;60(4):398-403.

3. Follmar KE, Debruijn M, Baccarani A, Bruno AD, Mukundan S, Erdmann D, Marcus JR. Concomitant injuries in patients with panfacial fractures. J Trauma. 2007;63(4):831-5.

4. Beogo R, Dakoure P, Savadogo LB, Coulibaly AT, Ouoba K. Associated injuries in patients with facial fractures: a review of 604 patients. Pan Afr Med J. 2013;16:119.

5. Dalena MM, Liu FC, Halsey JN, Lee ES, Granick MS. Assessment of panfacial fractures in the pediatric population. J Oral Maxillofac Surg. 2020;78(7):1156-61.

6. Park D, Cha B, Myung Y. Characteristics of panfacial fractures in the elderly: etiology, fracture patterns, concomitant injuries, and postoperative complication risk. J Craniofac Surg. 2020;31(5):1421-3.

7. Ali K, Lettieri SC. Management of panfacial fracture. Semin Plast Surg. 2017;31(2):108-17.

8. Tessier P. The classic reprint: experimental study of fractures of the upper jaw, I and II, Rene Le Fort MD. Plast Reconstr Surg. 1972;50(5):497-506.

9. Buitrago-Tellez CH, Schilli W, Bohnert M, Alt K, Kimmig M. A comprehensive classification of craniofacial fractures: postmortem and clinical studies with two- and three-dimensional computed tomography. Injury. 2002;33(8):651-68.

10. Ahmad Z, Nouraei R, Holmes S. Towards a classification system for complex craniofacial fractures. Br J Oral Maxillofac Surg. 2012;50(6):490-4.

11. Casale GG, Fishero BA, Park SS, Sochor M, Heltzel SB, Christophel JJ. Classifying and standardizing panfacial trauma with a new bony facial trauma score. JAMA Facial Plast Surg. 2017;19(1):23-8.

12. Bagheri SC, Dierks EJ, Kademani D, Holmgren E, Bell RB, Hommer L, Potter BE. Application of a facial injury severity scale in craniomaxillofacial trauma. J Oral Maxillofac Surg. 2006;64(3):408-14.

13. Aita TG, Pereira Stabile CL, Dezan Garbelini CC, Vitti Stabile GA. Can a facial injury severity scale be used to predict the need for surgical intervention and time of hospitalization? J Oral Maxillofac Surg. 2018;76(6):1280. e1281-1281.e1288.

14. Sahni V. Maxillofacial trauma scoring systems. Injury. 2016;47(7):1388-92. 
15. Ramalingam S. Role of maxillofacial trauma scoring systems in determining the economic burden to maxillofacial trauma patients in India. J Int Oral Health. 2015;7(4):38-43.

16. Levgen S, Vitaliy G, Oleksandr K, Andrey K. Prediction of mortality in severely injured patients with facial bone fractures. Oral Maxillofac Surg. 2021. https://doi.org/10.1007/s10006-021-00967-7.

17. Choi JW, Kim MJ. Treatment of panfacial fractures and three-dimensional outcome analysis: the occlusion first approach. J Craniofac Surg. 2019:30(4):1255-8.

18. Kim J, Choi JH, Chung YK, Kim SW. Panfacial bone fracture and medial to lateral approach. Arch Craniofac Surg. 2016;17(4):181-5.

19. Yun S, Na Y. Panfacial bone fracture: cephalic to caudal. Arch Craniofac Surg. 2018;19(1):1-2.

20. Wang L, Lee TS, Wang W, Yi DI, Sokoya M, Ducic Y. Surgical management of panfacial fractures. Facial Plast Surg. 2019;35(6):565-77.

21. Yang R, Zhang C, Liu Y, Li Z, Li Z. Why should we start from mandibular fractures in the treatment of panfacial fractures? J Oral Maxillofac Surg. 2012;70(6):1386-92.

22. Brucoli M, Boffano P, Broccardo E, Benech A, Corre P, Bertin H, Pechalova P, Pavlov N, Petrov P, Tamme T, et al. The "European zygomatic fracture" research project: the epidemiological results from a multicenter European collaboration. J Craniomaxillofac Surg. 2019;47(4):616-21.

23. Brucoli M, Boffano P, Pezzana A, Benech A, Corre P, Bertin H, Pechalova P, Pavlov N, Petrov P, Tamme T, et al. The "European Mandibular Angle" research project: the analysis of complications after unilateral angle fractures. Oral Surg Oral Med Oral Pathol Oral Radiol. 2019;128(1):14-7.

24. Brucoli M, Boffano P, Pezzana A, Benech A, Corre P, Bertin H, Pechalova P, Pavlov N, Petrov P, Tamme T, et al. The "European Mandibular Angle" research project: the epidemiologic results from a multicenter European collaboration. J Oral Maxillofac Surg. 2019;77(4):791.e791-791.e797.
25. Brucoli M, Boffano P, Romeo I, Corio C, Benech A, Ruslin M, Forouzanfar T, Starch-Jensen T, Rodriguez-Santamarta T, de Vicente JC, et al. Epidemiology of maxillofacial trauma in the elderly: a European multicenter study. J Stomatol Oral Maxillofac Surg. 2020;121(4):330-8.

26. Brucoli M, Boffano P, Romeo I, Corio C, Benech A, Ruslin M, Forouzanfar T, Starch-Jensen T, Rodriguez-Santamarta T, de Vicente JC, et al. Management of maxillofacial trauma in the elderly: a European multicenter study. Dent Traumatol. 2020;36(3):241-6.

27. Hwang K, You SH, Lee HS. Outcome analysis of sports-related multiple facial fractures. J Craniofac Surg. 2009;20(3):825-9.

28. Cooter RD, David DJ. Computer-based coding of fractures in the craniofacial region. Br J Plast Surg. 1989;42(1):17-26.

29. Zhang J, Zhang Y, El-Maaytah M, Ma L, Liu L, Zhou LD. Maxillofacial Injury Severity Score: proposal of a new scoring system. Int J Oral Maxillofac Surg. 2006;35(2):109-14

30. Catapano J, Fialkov JA, Binhammer PA, McMillan C, Antonyshyn OM. A new system for severity scoring of facial fractures: development and validation. J Craniofac Surg. 2010;21(4):1098-103.

31. Canzi G, De Ponti E, Fossati C, Novelli G, Cimbanassi S, Bozzetti A, Sozzi D. Understanding the relevance of comprehensive facial injury (CFI) score: statistical analysis of overall surgical time and length of stay outcomes. J Craniomaxillofac Surg. 2019;47(9):1456-63.

32. Canzi G, De Ponti E, Novelli G, Mazzoleni F, Chiara O, Bozzetti A, Sozzi D. The CFI score: validation of a new comprehensive severity scoring system for facial injuries. J Craniomaxillofac Surg. 2019;47(3):377-82.

\section{Publisher's Note}

Springer Nature remains neutral with regard to jurisdictional claims in published maps and institutional affiliations.
Ready to submit your research? Choose BMC and benefit from:

- fast, convenient online submission

- thorough peer review by experienced researchers in your field

- rapid publication on acceptance

- support for research data, including large and complex data types

- gold Open Access which fosters wider collaboration and increased citations

- maximum visibility for your research: over $100 \mathrm{M}$ website views per year

At BMC, research is always in progress.

Learn more biomedcentral.com/submissions 